\title{
Dual Feeding Antenna for Performance Enhancement of Next-Generation of Mobile Networks against Self-Interference
}

\author{
Ehab A. Hegazy, Mohamed Bakry El Mashade
}

\begin{abstract}
Actually, the interference phenomena appear in all current wireless communication systems. Generally, conventional wireless communication systems use two separate channels; one of them for transmitting and the other one for receiving. Achieving single channel full duplex (FD) represents one of the key challenges for the implementation of 5G. Single channel FD permits the capability of wireless communication system to transmit and get concurrently on the identical channel, as well as the assurance of an efficient utilization of the current spectrum. With this newest technology, another sort of interference, which is called self-interference, will be generated. Therefore, self-interference cancellation strategies have an awesome solution for the development of the next generation. Passive and active cancellation techniques can be used to remedy such type of interference. In this regard, a dual feeding antenna approach is regarded as passive cancellation. This paper is concerned with this type of self-interference cancellation. A patch antenna is simulated and tested for two resonance frequencies; 2.45 and 28 GHz. Both of these frequencies are frequency channel candidates proposed by international telecommunication union (ITU) for the fifth generation of mobile networks.
\end{abstract}

Keywords: Self-Interference Elimination, Mobile network Design.

\section{INTRODUCTION}

Through its technologies and devices, communication through cordless has become an ubiquitous part of recent life, from global cellular telephone systems to local and even personal-area networks. This strategy of communication involves the sending of information over a distance without the help of wires, cables or any other forms of electrical conductors. It is a broad term that incorporates all scenarios and styles of connecting and communicating between two or more devices using a wireless signal.

The world has witnessed significant progress through several generations of mobile communication technology. In these

Revised Manuscript Received on July 15, 2020

* Correspondence Author

Mohamed Bakry El_Mashade*, Electrical Engineering Department, Faculty of Engineering, Al_Azhar University, Cairo, Egypt. E-mail: mohamed.b.elmashade@azhar.edu.eg Engineering, Al_Azhar University, Cairo, Egypt. E-mail: ehab.hegazy@gmail.com

(C) The Authors. Published by Blue Eyes Intelligence Engineering and Sciences Publication (BEIESP). This is an open access article under the CC BY-NC-ND license (http://creativecommons.org/licenses/by-nc-nd/4.0/) generations, Frequency as well as time division duplex, Antenna

Ehab A. Hegazy, Electrical Engineering Department, Faculty of

specified forms, each new one enlarging the capabilities and promoting the end-user experience in comparison with the previous strategy, as Fig.(1) demonstrates. On the other hand, the key drivers behind the success of the telecom industry include the rapid adaptation of telecommunication techniques and services by different sectors of society, as well as parallel development of advanced technologies from both hardware and software framework points of view. This success has come a long way from the appearance of the first approach $(1 \mathrm{G})$ cellular technology to the present day's strategy of this technology (4G).

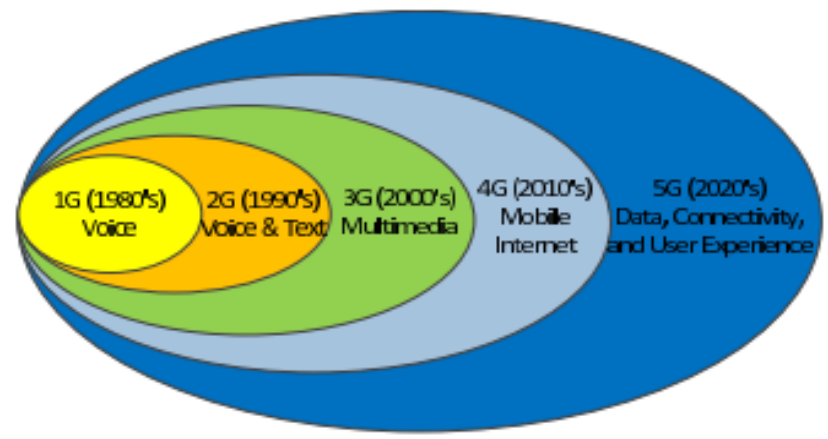

Fig.(1) Service classes evolution over wireless mobile generations

Recently, since we are dealing with "internet of things", 5G is anticipated to accomplish the entire demands that have not been fulfilled by 4G. As shown in Fig.(2), 5G technologies are expected to prepare ultra-high bandwidth, extremelyhigh data rate, extra-low latency, highly speed mobility, and high energy efficiency. In other words, 5G will allow the use of much greater spectrum allocations at untapped mm-wave frequency bands, much higher bit rates in larger portions of the coverage area, higher aggregate capacity for many simultaneous users in both licensed and unlicensed spectrum, lower outage probability, longer battery life, lower infrastructure costs, and highly directional beam forming antennas at both the mobile device and base station. Additionally, the 5G backbone networks will replace copper and fiber communications with mm-wave wireless connections, which lead to rapid deployment as well as mesh-like connectivity with cooperation among base stations.

Published By:

Blue Eyes Intelligence Engineering

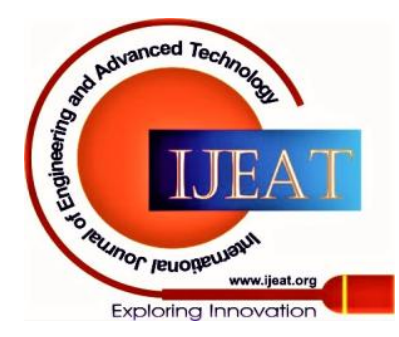




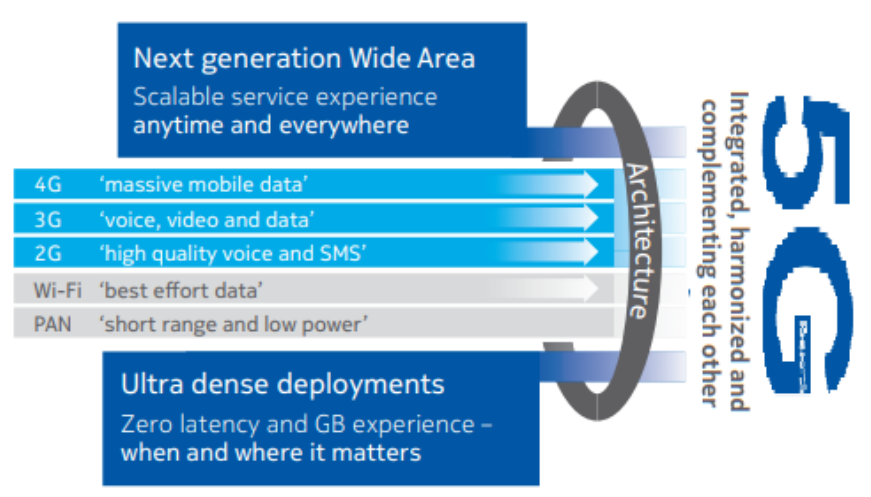

Fig.(2) Integration of existing and new services

As in all available mobile systems, the existing wireless communication systems employ two different channels to establish the transceiver process. They can't transmit and receive on the identical frequency channel per time slot. Additionally, transmission mode is not evolved, even long term evolution (LTE) still continuing via frequency division or time division duplex (FDD or TDD). Thus, achieving single full duplex will give us a great chance to enhance the future of 5G. In addition, it allows the current spectrum to be adequately utilized. Moreover, it eliminates the frequency and time constraints. However, through exploitation of the pronounced merits of single channel, self-interference (SI) will be generated. Transmitted antenna represents the main source of such type of interference due to its high power [3]. In telecommunication, a micro strip antenna refers to an antenna fabricated with micro strip mechanism on a printed circuit board. This type of antennas is usually employed at microwave frequencies. From the fabrication point of view, a micro strip antenna is composed of a patch of metal foil on the surface of a printed circuit board, with a metal foil ground plane on the other side of the board. The patch style is the most common type of micro strip antenna. A patch antenna is usually of narrowband [4].

The greatest part of micro strip antennas composed of several patches in a 2-D array. In recent decades, micro strip antenna has become very popular owing to its thin planar profile which allows it to be incorporated into the surfaces of consumer products, aircraft and missiles. Additionally, the ease of its fabrication using printed circuit techniques; the ease of integrating it on the same board with the rest of the circuit, and the possibility of adding active devices to the antenna itself to produce active ones makes it widely used in practical applications [5].

The intensity of SI is a crucial parameter owing to its influence on the performance of any wireless communication system. Hence, the proposed self-interference cancellation (SIC) technique depends upon a smart approach to overcome this problem which in turn will enhance the usage of the current spectrum. Generally, SIC scenario acts as a backbone for the deployment of single channel in the forthcoming version of mobile networks. The cancellation of SI should be achieved via antenna scheme, RF fragment, and analogue \& digital signal processing. This achievement can be formulated in two main scenarios; the first one is related to electromagnetic separation which is termed as passive cancellation, whilst the other one can called as active cancellation [6]. The remaining part of this paper is organized as follows. In section II self-interference cancellation techniques are overviewed. Section III is concerned with discussing the antenna technique of interference cancellation. Our proposed design procedure along with its simulation results is the objective of section IV. Finally, section V extracts our concluded remarks.

\section{SIC TECHNIQUES}

Wireless communications have been associated with cellular telephony for long time and have their highest impact on everyday lives. In recent times, wireless computer networks have led to a significant change in working routines and mobility of workers. Besides these widely publicized cases, wireless sensor networks monitor factories, wireless links replace the cables between computers and keyboards, and wireless positioning systems monitor the location of trucks that have goods identified by wireless RF labels. This variety of novel applications creates technical challenges for the wireless designers to become bigger with each day.

SI cancellation procedures familiarize a best solution in upcoming of the next generation of mobile communication through realizing single channel. Traditional editions of mobile communication systems have the proficiency of choice since it can turn as transceiver concurrently either on the same frequency segment with time varying (TDD) or on another frequency resource (FDD). The algorithms of SIC have several forms. However, most research work announced that cancellation techniques can be classified into two basic forms: passive and active. Passive cancellation technique takes place on the level of an antenna module. Meanwhile, the active strategy of cancellation is dependent on both analogue and digital processes. Active cancellation can be implemented via combination of RF segment along with some digital processing. This scenario of cancellation is based on subtracting the SI signals from the received signal. The subtraction process will be performed through digital samples and analogue signal. Several types of active SIC are essentially exist [5-6]. In full duplex (FD) system, an active SIC can be accomplished via balanced to unbalanced transformation which is entitled as a balun. An inverse SI signal, which is produced by balun, is an expedient to revoke SI. Balun will obtain a positive signal from transmitted antenna which is the causing of SI signal. In order to match the received signal, a combination process will be executed for both the received and inversed signals. Additionally, some adjustments, such as delay and attenuation, can be employed in the preparation of an inverse signal [7]. According to [6, 8] Table I displays a brief summary of RF solution for SIC approaches.

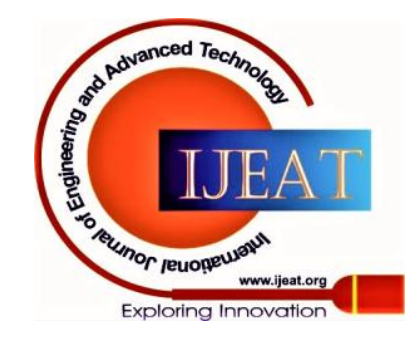


Table I Antenna used according to each technique

\begin{tabular}{||l||c|}
\hline \multicolumn{1}{|c||}{ RF SIC Technique } & $\begin{array}{l}\text { NO of } \\
\text { Antennas }\end{array}$ \\
\hline \hline $\begin{array}{l}\text { Combination of a variable attenuator and } \\
\text { phase shifter }\end{array}$ & $\begin{array}{c}\text { One } \\
\text { general }\end{array}$ \\
\hline \hline Fed-forward cancellation with two fed & $\begin{array}{c}\text { One } \\
\text { specific }\end{array}$ \\
\hline \hline Balanced/unbalanced (balun) transformer & Two \\
\hline \hline $\begin{array}{l}\text { Antenna cancellation using two transmit } \\
\text { and one receive antennas }\end{array}$ & Three \\
\hline \hline $\begin{array}{l}\text { 1) QHx220 noise cancellers } \\
\text { 2) A nulling transmit antenna }\end{array}$ & Two \\
\hline \hline $\begin{array}{l}\text { 1) QHx220 noise cancellers } \\
\text { 2) Transmit antenna } \\
\text { 3) Digital cancellation }\end{array}$ & Three \\
\hline \hline
\end{tabular}

QHx 220 noise dominance chip is used to remove a known analogue interference from received signal. The transmitted signal of the antenna feeds the QHx220 via a wire. Through the use of QHx220 noise canceller, a subtraction process is applied to both interfering signal and received signal in order to improve the beneficial signal $[6,8]$. Other methods for SIC can be implemented by eliminating SI, in the analogue signal stage, in accordance with the phase of the two signals [8].

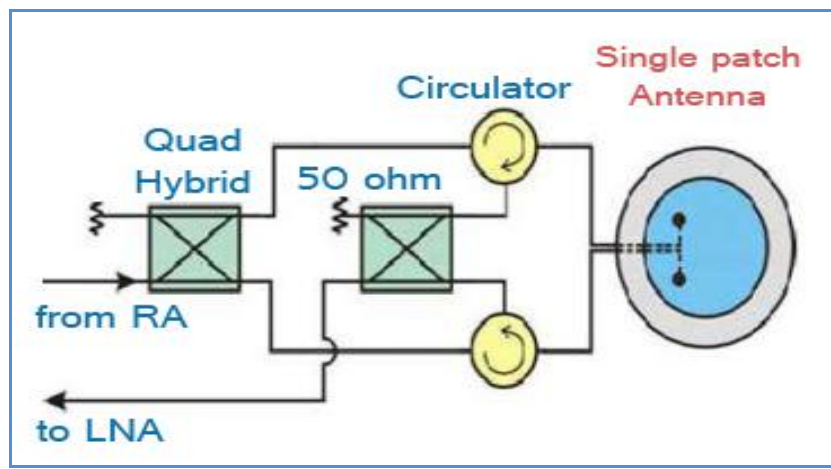

Fig.(3) Two-fed patch antenna for passive cancellation

\section{ANTENNA CANCELLATION}

An antenna system can be considered as the eye of each wireless communication system. Through the existence of self-interference problem, an antenna acts as a foremost part in passive SIC procedure, as Table I demonstrates.

Here, the proposed work offers one of the existing mechanisms which includes an antenna with dual feed in order to enhance the intensity of SIC. As Fig.(3) depicts, the existing antenna has the ability of transmitting and getting signals by means of polarization diversity. It is significant to note that feeding spots are orthogonal and have similar amplitudes. In our research, we select two resonance frequencies of values $2.45 \mathrm{GHz}$ and $28 \mathrm{GHz}$. Aiming that our proposed strategy will be useful for the future of $5 \mathrm{G}$.

\section{ANTENNA DESIGN, SIMULATION RESULTS}

In wireless communication, antenna plays the most prominent part in radiating the information of interest. In this regard, micro strip patch antenna is well known to have positive features for cost-effective, low profile and broadband. Additionally, it is an evident choice for wireless devices due to its practical characteristics like low fabrication cost, light weight and volume, and a low profile configuration in comparison with the other bulky type of antennas. Moreover, it can be easily mounted on rockets, missiles and any conformal shaped satellites without major modification. Furthermore, arrays of these antennas can simply be produced. Owing to these important merits, this type of antenna is of practical use in many applications.

Now, we are going to design the suggested antenna following the micro strip patch antenna rules [9-11].

\section{A. Proposed Antenna Design Configuration}

The design specification of a patch antenna is characterized by three vital factors. These parameters are: the operative frequency $\left(f_{\mathrm{r}}\right)$, substrate dielectric constant $\left(\varepsilon_{\mathrm{r}}\right)$, and the dielectric substrate height (h). In the subsequent text, the design procedure is tabulated. Firstly, the antenna width can be calculated with the aid of the following formula:

$$
W=\frac{c_{0}}{2 f_{r}} \sqrt{\frac{2}{\varepsilon_{r}+1}}
$$

where $\mathrm{c}_{0}$ denotes is the free-space velocity of light.

One the other hand, the effective dielectric constant has a mathematical expression given by:

$$
\varepsilon_{\text {reff }}=\frac{\varepsilon_{r}+1}{2}+\frac{\varepsilon_{r}-1}{2} \sqrt{\frac{1}{1+12 h / W}} \& \quad \frac{W}{h}>>1
$$

For a given resonance frequency $f_{\mathrm{r}}$, the effective length takes the form:

$$
L_{e f f}=\frac{c_{0}}{2 f_{r}} \sqrt{\frac{1}{\varepsilon_{r_{e f f}}}}
$$

The normalized extension in the antenna length can be obtained via the formula:

$$
\frac{\Delta L_{\text {eff }}}{h}=0.412 \frac{\left(\varepsilon_{r_{\text {eff }}}+0.3\right)(W / h+0.264)}{\left(\varepsilon_{r_{\text {eff }}}-0.258\right)(W / h+0.8)}
$$

As a function of $\mathrm{L}_{\text {eff }} \& \Delta \mathrm{L}_{\text {eff }}$, the actual length of the designed antenna can be evaluated as:

$$
L_{\text {eff }}=L+2 \Delta L
$$

The proposed antenna feeding is accomplished through a micro strip line technique. In our design procedure, we will calculate the length and width of matching transmission line which are indicated as Lm1 \& Wm1for port one, as Fig.(4) depicts. Meanwhile, the length and width of feed micro strip line are computed and are denoted as Lt1 \& Wt1 for port one. The design is performed in accordance with micro strip patch antenna rules [11, 12]. Additionally, similar calculations are performed for the second port.

\section{B. Simulation results and Discussion}

The performance analysis of the underlined antenna is carried out using CST software [12].

Published By:

Blue Eyes Intelligence Engineering and Sciences Publication

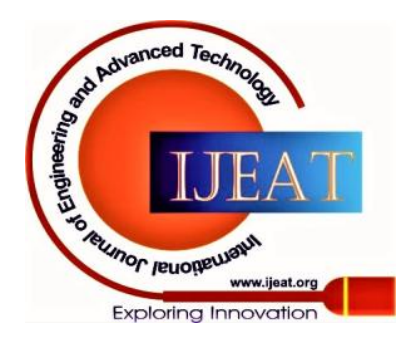




\section{Subdivision 1}

The proposed patch antenna working at $2.45 \mathrm{GHz}$ is of $1.5 \mathrm{~mm}$ substrate height.

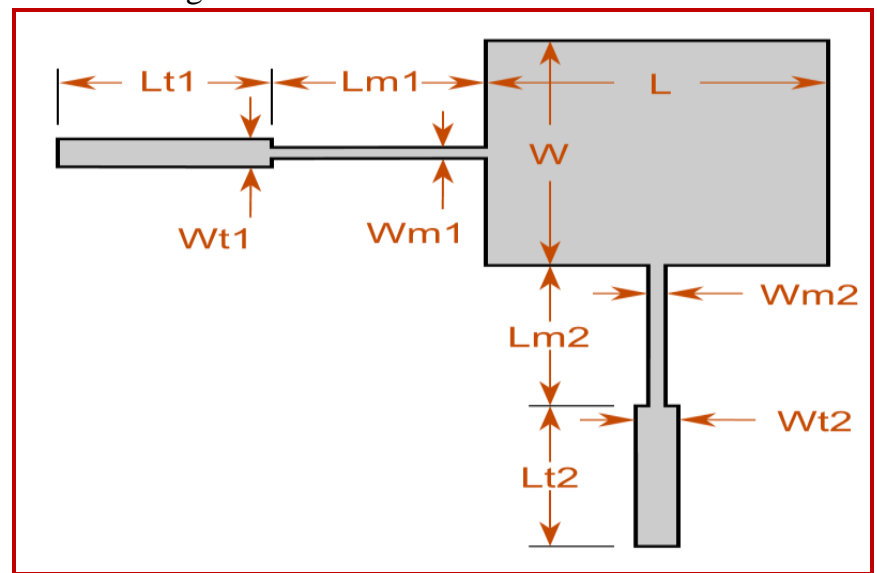

Fig.(4) Dual micro strip-edge-fed circularly polarised rectangular patch antenna

We confer to the design specifications in order to complete the plan of the under examination patch antenna. These parameters are listed in Table II which shows dual-fed circularly polarized patch design objectives. Moreover, Table III outlines the physical parameters of our proposed design.

Table II Dual-fed circularly polarised patch design objective

\begin{tabular}{|c|l|c|}
\hline Name & \multicolumn{1}{|c|}{$\begin{array}{c}\text { Description } \\
\text { fontre frequency }\end{array}$} & $\begin{array}{c}\text { Value } \\
\mathbf{2 . 4 5}\end{array}$ \\
\hline $\mathbf{R H z}$ & Input resistance at port 1 & $\mathbf{5 0} \Omega$ \\
\hline $\mathbf{R} 2$ & Input resistance at port 2 & $\mathbf{5 0} \Omega$ \\
\hline $\mathbf{P}$ & $\begin{array}{l}\text { Polarization } \\
\text { (transmitting) }\end{array}$ & linear \\
\hline Name & $\begin{array}{l}\text { Substrate: The substrate } \\
\text { name. }\end{array}$ & FR-4 \\
\hline
\end{tabular}

Table III Dual-fed circularly polarised design parameters for $2.45 \mathrm{GHz}$ antenna

\begin{tabular}{|c|c|c|}
\hline Name & Description & Value \\
\hline $\mathbf{L}$ & Length of the patch element & $\begin{array}{l}26.19 \\
\mathrm{~mm}\end{array}$ \\
\hline $\mathbf{W}$ & Width of the patch element & $\begin{array}{l}29.01 \\
\mathrm{~mm}\end{array}$ \\
\hline Lm1 & $\begin{array}{l}\text { Length of matching } \\
\text { transmission line (port 1) }\end{array}$ & $\begin{array}{l}18.18 \\
\mathrm{~mm}\end{array}$ \\
\hline Wm1 & $\begin{array}{l}\text { Width of matching } \\
\text { transmission line (port 1) }\end{array}$ & $\begin{array}{l}159.7 \\
\mu \mathrm{m}\end{array}$ \\
\hline Lt1 & $\begin{array}{l}\text { Length of feed microstrip line } \\
\text { (port 1) }\end{array}$ & $\begin{array}{l}16.84 \\
\mathrm{~mm}\end{array}$ \\
\hline Wt1 & $\begin{array}{l}\text { Width of feed microstrip line } \\
\text { (port 1) }\end{array}$ & $\begin{array}{l}2.892 \\
\mathrm{~mm}\end{array}$ \\
\hline Lm2 & $\begin{array}{l}\text { Length of matching } \\
\text { transmission line (port 2) }\end{array}$ & $\begin{array}{l}18.18 \\
\mathrm{~mm}\end{array}$ \\
\hline Wm2 & $\begin{array}{l}\text { Width of matching } \\
\text { transmission line (port 2) }\end{array}$ & $\mu^{159.7}$ \\
\hline Lt2 & $\begin{array}{l}\text { Length of feed microstrip line } \\
\text { (port 2) }\end{array}$ & $\begin{array}{l}16.84 \\
\mathrm{~mm}\end{array}$ \\
\hline Wt2 & $\begin{array}{l}\text { Width of feed microstrip line } \\
\text { (port 2) }\end{array}$ & $\begin{array}{l}2.892 \\
\mathrm{~mm}\end{array}$ \\
\hline
\end{tabular}

Published By:

Blue Eyes Intelligence Engineering and Sciences Publication examined antenna. investigated is the maximum power transferring which is considered as an indication about the matching between the feed line and the input impedance of the antenna. In this situation, S11 represents the insertion loss of an antenna. It designates the amount of power that is lost to the load and doesn't return as a reflection. It clarifies how well the matching between the transmitter and antenna has taken place. In other words, insertion loss is consistent with the ratio of the reflected power to that of input of an antenna.

Generally, antenna radiates efficiently for particular range of frequencies. At these frequencies, the radiated power is almost equal to the input power, which means that the reflected power is of negligible value. Based on this principal background, a graph of S11 of an antenna versus frequency represents its return loss. For optimum operating conditions, such a graph must exhibit a dip at the operating frequency, i.e., a minimum $\mathrm{dB}$ value at this frequency. So, the expected behavior of S11 for an antenna would be a flat line throughout the frequency scale with deep dip at its operating frequency range. On the other hand, scattering parameters of an antenna can be defined as the correlation or the relationship between its ports [14]. For case in point, S12 represents the power transferred from port 2 to port 1 whilst S21 indicates the reverse, i.e.; it refers to the power transferred from port 1 to port 2. Fig.(5) illustrates the estimated result of the reference antenna. It plots S12 and S21 versus frequency indicating the fundamental resonance frequency. In other words, Fig.(5) demonstrates a high isolation between the two ports of the

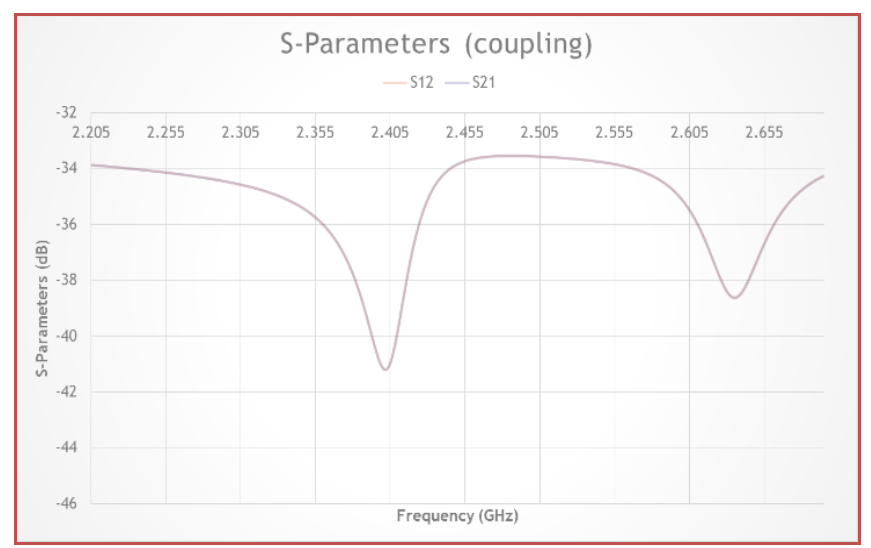

Fig.(5) S12 and S21 of the patch antenna resonating at $2.45 \mathrm{GHz}$.

Table IV Average S-parameters of dual-fed circularly polarised Antenna

\begin{tabular}{|l|c|c|}
\hline \multicolumn{3}{|c|}{ Dual port Antenna 2.45GHZ } \\
\hline & $\mathrm{S} 12$ & $\mathrm{~S} 21$ \\
\hline Average S-parameters & $-35.17 \mathrm{~dB}$ & $-35.17 \mathrm{~dB}$ \\
\hline $\begin{array}{l}\text { Bandwidth below( -10dB } \\
\text { level) }\end{array}$ & $490 \mathrm{MHZ}$ & $490 \mathrm{MHZ}$ \\
\hline
\end{tabular}


The radiation pattern of an antenna is a description of its far-field radiation characteristics as a three-dimensional plot in which $\theta$ denotes the angle of elevation and $\varphi$ represents the azimuth angle. More specifically, it is a plot of the radiated power of an antenna per unit solid angle [11]. Figs.(6 \& 7) depict the far field gain of the underlined antenna at $\varphi=0^{\circ}$ and $\varphi=90^{\circ}$, respectively. As demonstrated in Fig.(8), the proposed antenna achieve an accepted radiation pattern with directivity of about $7.221 \mathrm{dBi}$.

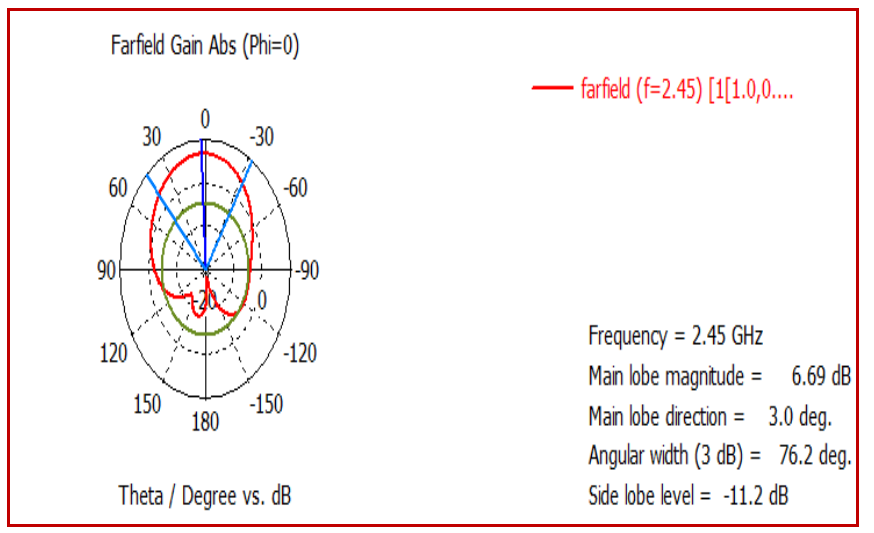

Fig.(6) Dual microstrip-edge-fed circularly polarised patch antenna radiation pattern at $2.45 \mathrm{GHz}$, for $\varphi=0^{\circ}$
Farfield Gain Abs (Phi=90)

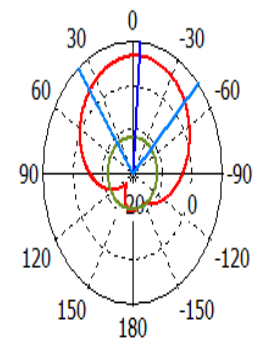

Theta / Degree vs. dB

\section{— farfield $(f=2.45)[1[1,0,0 \ldots$}

Frequency $=2.45 \mathrm{GHz}$

Main lobe magnitude $=6.71 \mathrm{~dB}$ Main lobe direction $=-5.0$ deg. Angular width $(3 \mathrm{~dB})=83.8 \mathrm{deg}$. Side lobe level $=-18.2 \mathrm{~dB}$
Fig.(7) Dual microstrip-edge-fed circularly polarised patch antenna radiation pattern at $2.45 \mathrm{GHz}$, for $\varphi=90^{\circ}$

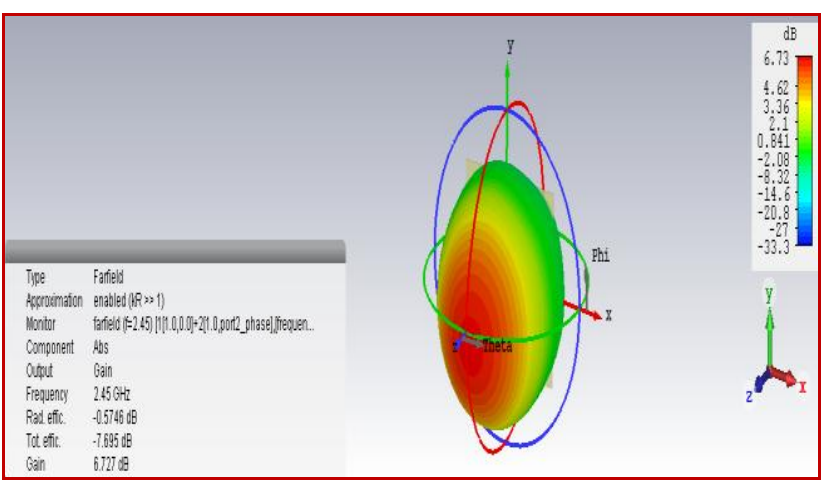

\section{Fig.(8) Dual micro strip-edge-fed CP radiation pattern plot}

Fig.(9) shows far field versus angle at the designed frequency for $\varphi=0^{\circ}$. Fig.(10) illustrates the same thing as Fig.(9) for $\varphi=90^{\circ}$.

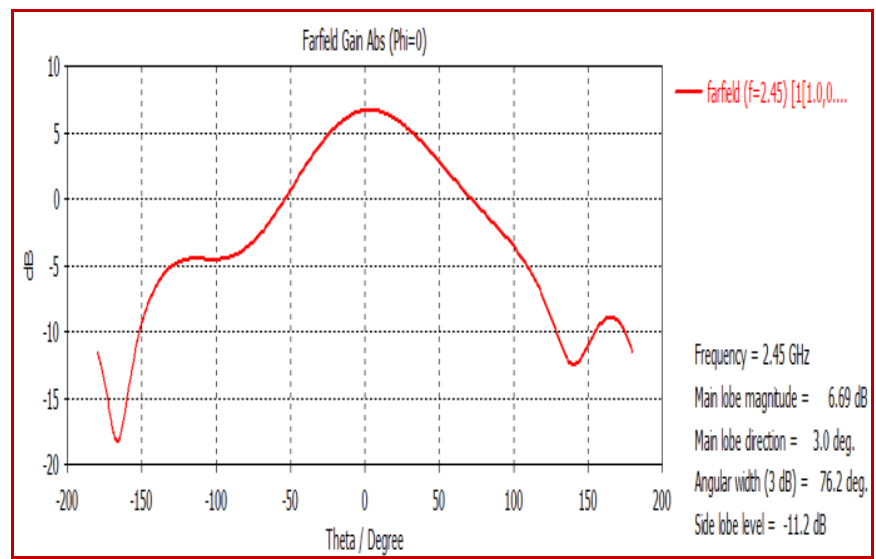

Fig.(9) Far field versus angle plot for $\phi=0^{\circ}$

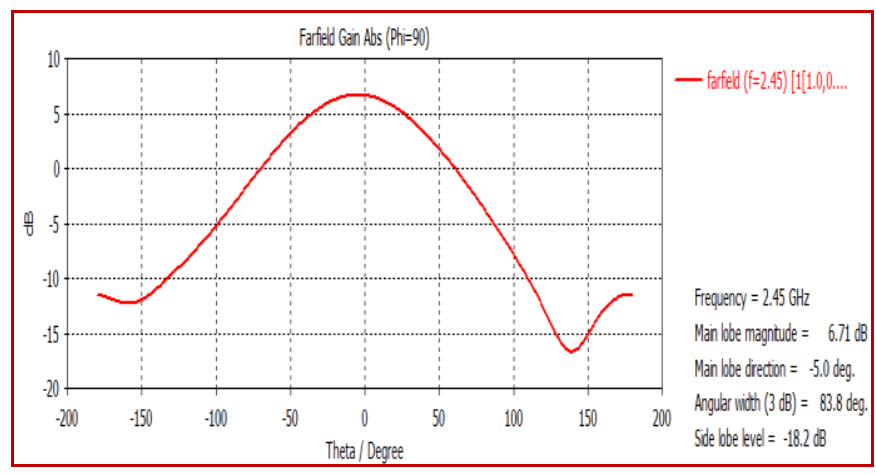

Fig.(10) Far field plot as a function of angle for $\phi=90^{\circ}$

Commonly the axial ratio (AR) is deployed in order to determine the quality of antenna polarization with dual feed [15]. Figs.(11 \& 12) clarify the polar and 3D plot for axial ratio of the suggested antenna.

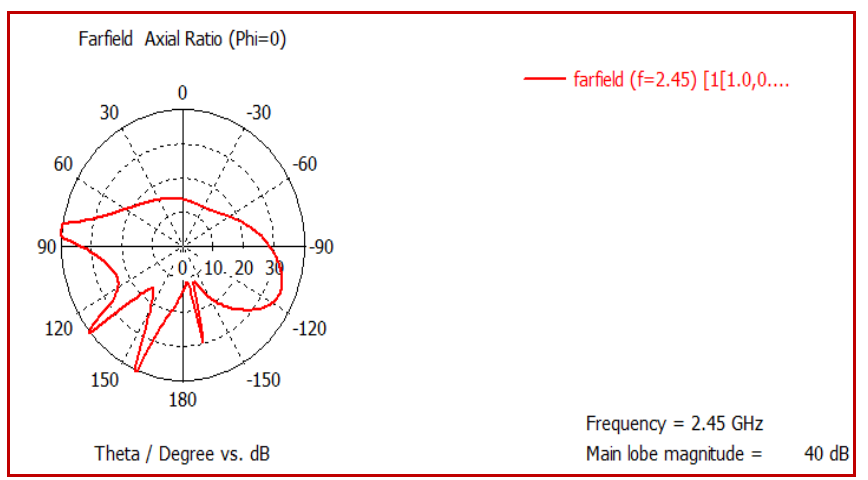

Fig.(11) Polar plot of axial ratio pattern for proposed antenna

Published By:

Blue Eyes Intelligence Engineering 


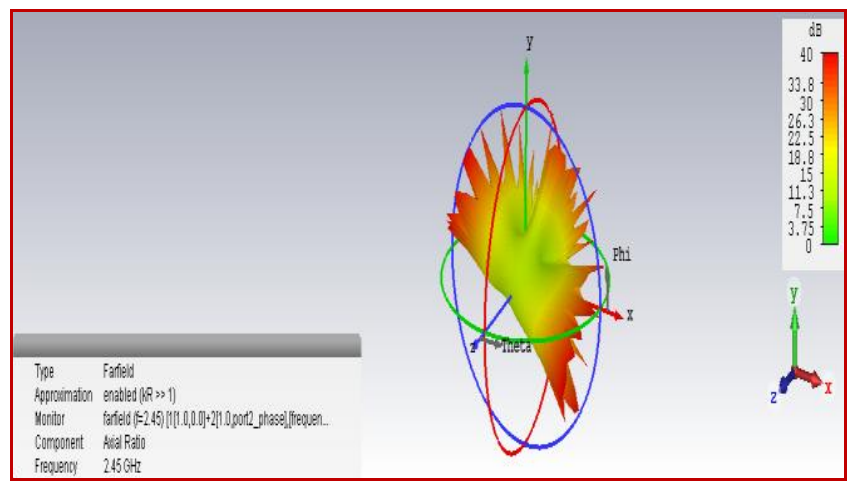

Fig.(12) Axial ratio pattern of the tested antenna

\section{Subdivision II}

Now, we turn our attention to the proposed patch antenna with $100 \mu \mathrm{m}$ substrate height and designed for operating at $28 \mathrm{GHz}$ resonance frequency through the same design objectives of 2.45GHz. This antenna has a preview displayed in Fig.(13).

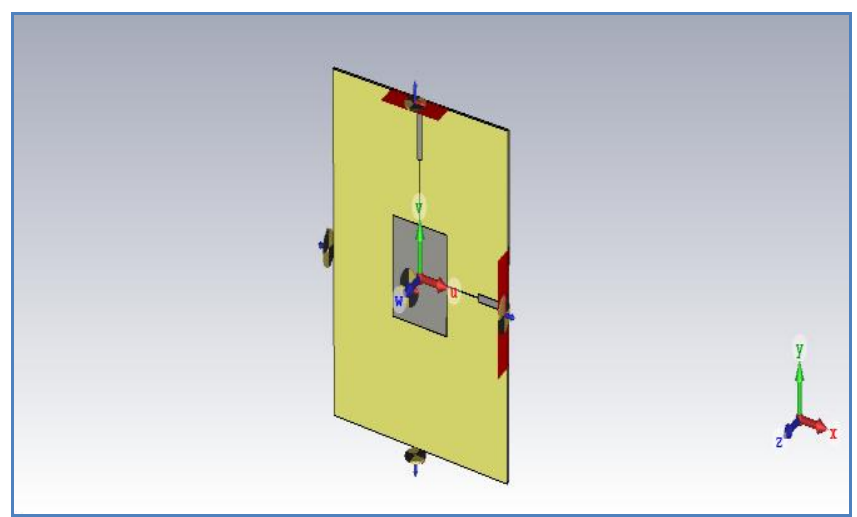

Fig.(13) Dual microstrip-edge-fed CP patch antenna preview

The physical parameters of the second proposed antenna are listed in Table V.

Table V Dual-fed circularly polarised design parameters for $28 \mathrm{GHz}$ antenna

\begin{tabular}{|c|c|c|}
\hline Name & Description & Value \\
\hline $\mathrm{L}$ & Length of the patch element & $\begin{array}{l}2.500 \\
\mathrm{~mm}\end{array}$ \\
\hline $\mathrm{W}$ & Width of the patch element & $\begin{array}{l}2.750 \\
\mathrm{~mm}\end{array}$ \\
\hline Lm1 & $\begin{array}{l}\text { Length of matching transmission line } \\
\text { (port 1) }\end{array}$ & $\begin{array}{l}1.592 \\
\mathrm{~mm}\end{array}$ \\
\hline Wm1 & $\begin{array}{l}\text { Width of matching transmission line } \\
\text { (port 1) }\end{array}$ & $\begin{array}{l}10.14 \\
\mu \mathrm{m}\end{array}$ \\
\hline Lt1 & Length of feed microstrip line (port 1) & $\begin{array}{l}1.474 \\
\mathrm{~mm}\end{array}$ \\
\hline Wt1 & Width of feed microstrip line (port 1) & $\begin{array}{l}192.8 \\
\mu \mathrm{m}\end{array}$ \\
\hline Lm2 & $\begin{array}{l}\text { Length of matching transmission line } \\
\text { (port 2) }\end{array}$ & $\begin{array}{l}1.592 \\
\mathrm{~mm}\end{array}$ \\
\hline Wm2 & $\begin{array}{l}\text { Width of matching transmission line } \\
\text { (port 2) }\end{array}$ & $\begin{array}{l}10.14 \\
\mu \mathrm{m}\end{array}$ \\
\hline Lt2 & Length of feed microstrip line (port 2) & $\begin{array}{l}1.474 \\
\mathrm{~mm}\end{array}$ \\
\hline $\mathrm{Wt} 2$ & Width of feed microstrip line (port 2) & $\begin{array}{l}192.8 \\
\mu \mathrm{m}\end{array}$ \\
\hline
\end{tabular}

Fig.(14) clarifies the estimated scattering parameters, such as S12 and S21, of the proposed patch antenna versus frequency indicating its fundamental resonance frequency. S12 and S21 are around 36.762dB.

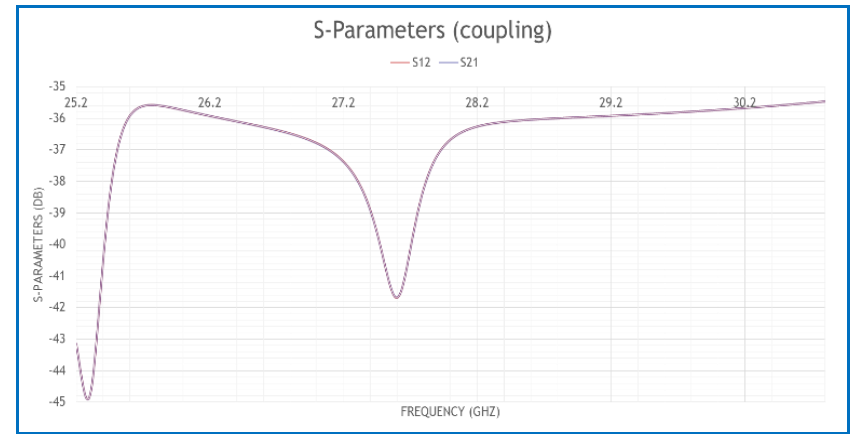

Fig.(14) Scattering parameters, S12 \& S21, of circularly polarised patch antenna radiation pattern at $28 \mathrm{GHz}$

Table VI Average S-parameters of dual-fed circularly polarised Antenna

\begin{tabular}{|l|c|c|}
\hline \multicolumn{3}{|c|}{ Dual port Antenna $28 \mathrm{GHZ}$} \\
\hline & $\mathrm{S} 12$ & $\mathrm{~S} 21$ \\
\hline Average S-parameters & $-36.75 \mathrm{~dB}$ & $-36.75 \mathrm{~dB}$ \\
\hline $\begin{array}{l}\text { Bandwidth below( -10dB } \\
\text { level) }\end{array}$ & $5.6 \mathrm{GHZ}$ & $5.6 \mathrm{GHZ}$ \\
\hline
\end{tabular}

Table VI indicates the antenna bandwidth and average values of S12 and S21. The polar plots at $\varphi=0^{\circ}$ and $\varphi=90^{\circ}$ are shown in Figs.(15 \& 16), respectively.

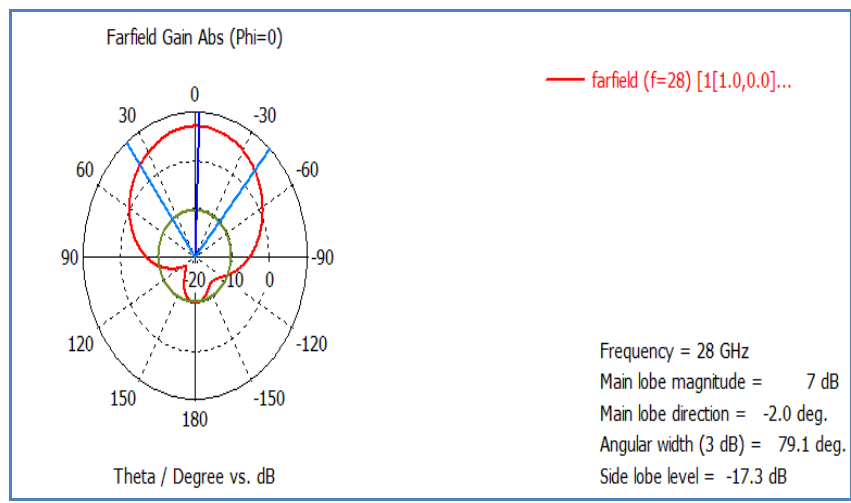

Fig.(15) Dual microstrip-edge-fed circularly polarised patch antenna radiation pattern at $28 \mathrm{GHz}$, for $\varphi=0^{\circ}$

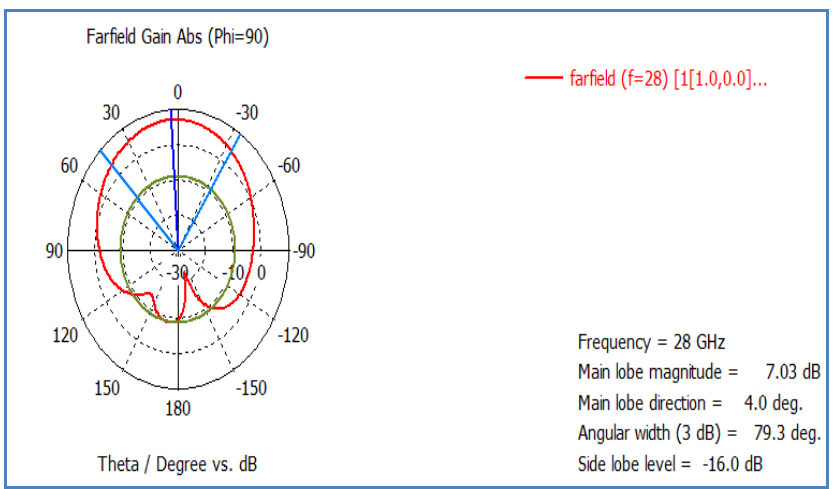

Fig.(16) Dual microstrip-edge-fed circularly polarised patch antenna radiation pattern at $28 \mathrm{GHz}$, for $\varphi=90^{\circ}$

Published By:

Blue Eyes Intelligence Engineering and Sciences Publication

(C) Copyriaht: All rights reserved.

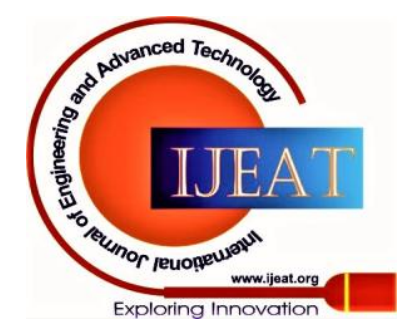




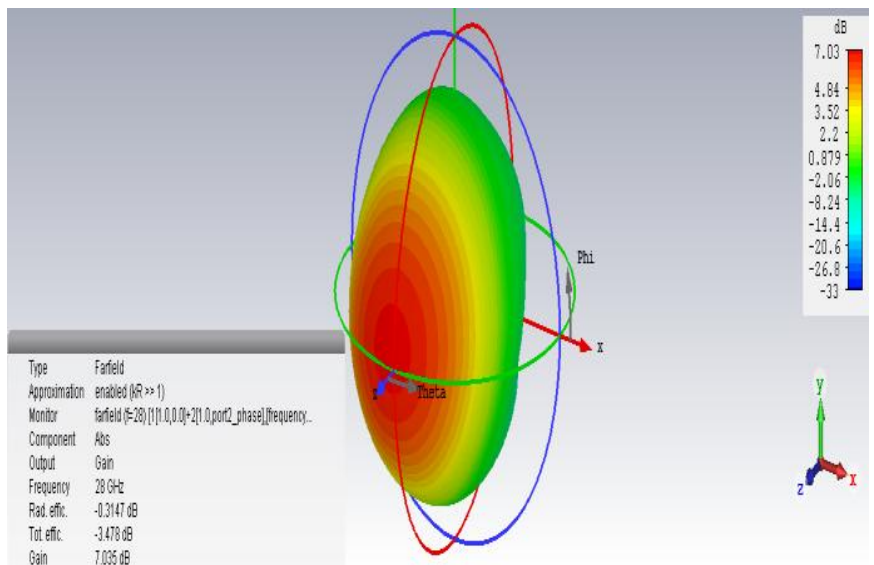

Fig.(17) Dual micro strip-edge-fed CP radiation pattern plot

As revealed in Fig.(17), the proposed antenna attains an accepted radiation pattern with directivity of about 7.329dBi. Fig.(18) shows the far field, as a function of angle, of the designed antenna at $\varphi=0^{\circ}$. Fig.(19) illustrates the same thing as Fig.(18) for $\varphi=90^{\circ}$.

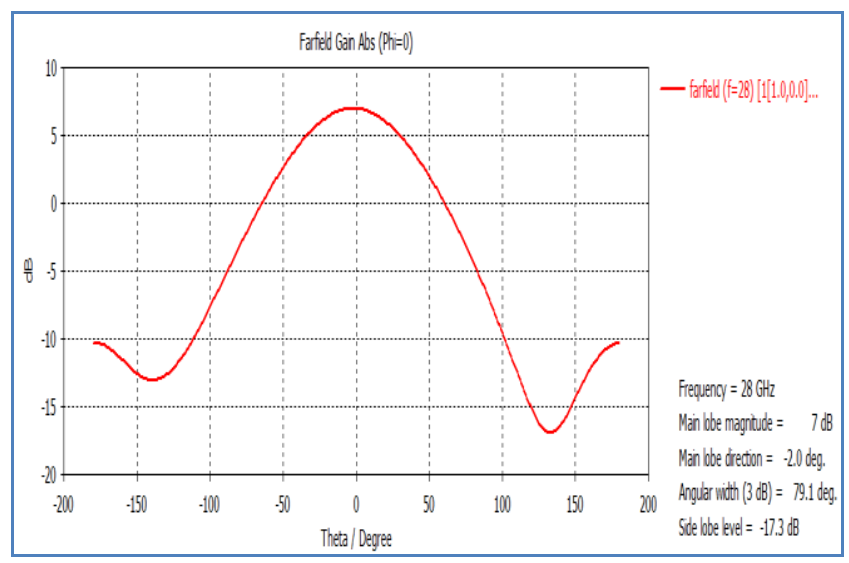

Fig.(18) Far field, as a function of angle, plot of $28 \mathrm{GHz}$ designed antenna for $\varphi=0^{\circ}$

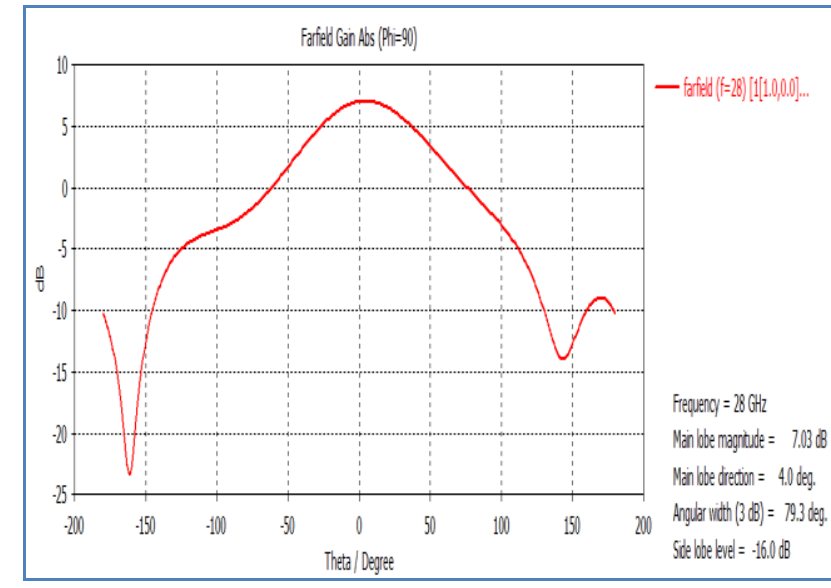

Fig.(19) Far field, as a function of angle, plot of $28 \mathrm{GHz}$ designed antenna for $\varphi=90^{\circ}$

Subsequently, Figs.(20 \& 21) demonstrate the polar and 3D, respectively, plots for axial ratio of the examined antenna.

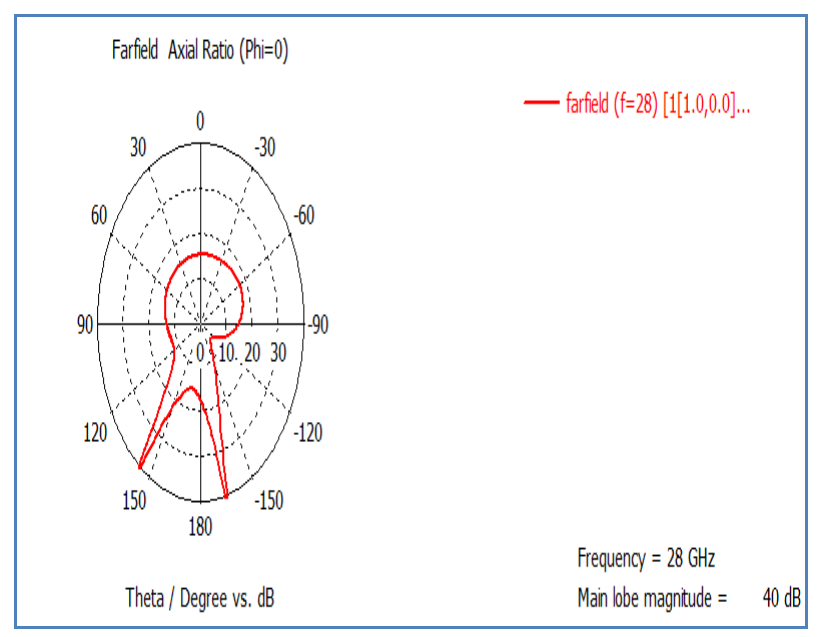

Fig.(20) Axial ratio pattern of $28 \mathrm{GHz}$ designed antenna

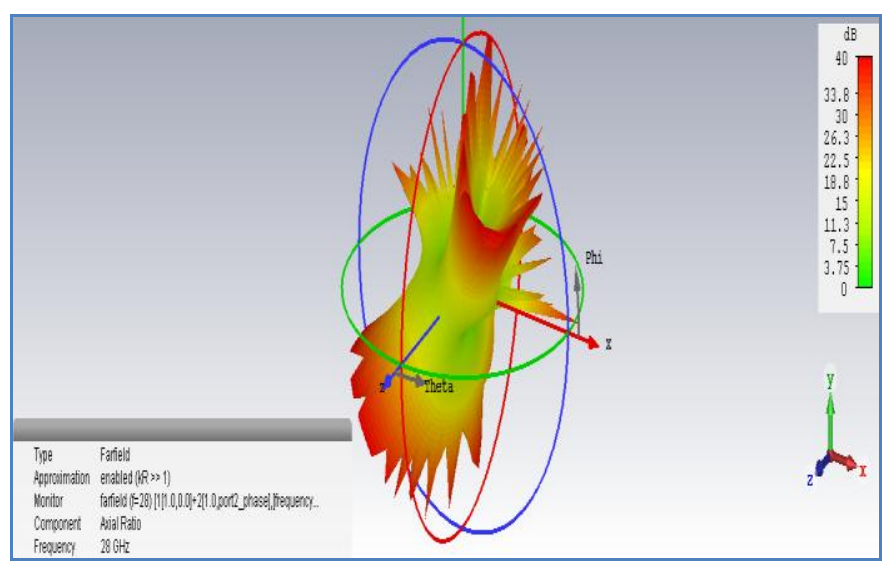

Fig.(21) Axial ratio pattern of the $28 \mathrm{GHz}$ tested antenna

\section{Design Summary of Proposed Antenna}

Our proposed antenna has the ability of transmitting and getting signals by means of polarization diversity. It is significant to note that feeding spots are orthogonal and have similar amplitude. Table VII summarizes the main parameters used in our design along with the gain of each antenna in terms of its resonance frequency.

Table VII Average S-parameters of Dual-fed circularly polarised Antenna

\begin{tabular}{|l|c|c|}
\hline \multicolumn{3}{|c|}{ Dual port Antenna } \\
\hline & $2.45 \mathrm{GHz}$ & $28 \mathrm{GHz}$ \\
\hline Dielectric substrate & FR-4 & FR-4 \\
\hline Substrate permittivity $\left(\varepsilon_{\mathrm{r}}\right)$ & 4.35 & 4.35 \\
\hline substrate height & $1.5 \mathrm{~mm}$ & $100 \mu \mathrm{m}$ \\
\hline Antenna gain( directivity) & $7.221 \mathrm{dBi}$ & $7.329 \mathrm{dBi}$ \\
\hline
\end{tabular}

The proposed work is considered as one of SIC techniques which are already used to improve or reduce the intensity of SI in wireless systems and this in turn will overcome the limitations of full duplex communication via effective propagation isolation between transmitted and received signals. Numerous dissimilar cancellation approaches are outlined in [16-18].

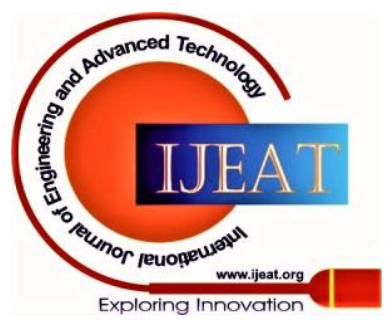


In these literatures, it is indicated that through this type of SIC algorithms, which is called antenna isolation technique, an isolation of about 20-30 dB can be provided. In our proposed antenna, we succeeded to achieve an isolation, between ports of antenna, in the order of $34 \mathrm{~dB}$ for resonance frequency of $2.45 \mathrm{GHz}$ and of $36 \mathrm{~dB}$ in the case of $28 \mathrm{GHz}$

\section{CONCLUSION}

$5 \mathrm{G}$ is predicted to provide attractive landscapes such as huge connections, reducing the latency down to one millisecond and enhancing the data rate up to $10 \mathrm{~Gb} / \mathrm{s}$. Extending full duplex communication to a longer range could remain a primarily challenge owing to growing of the spectral efficiency along with more occupation of frequency spectrum. One of the major challenges in 5G future is the realizing of single channel full duplex. Self-interference cancellation is a mandatory and attractive solution for more utilization of the current spectrum. Several self-interference cancellation techniques are deployed in wireless systems. Our proposed work is applied to achieve such objective for 2.45 and $28 \mathrm{GHz}$.

\section{REFERENCES}

1. Zhan Xu, Jienan Liu, Wei Zhang, Shidong Zhou, Weuqi Waug, "Capacity analysis and comparison for cellular systems over different frequency bands", IEEE International Conference on Network Infrastructure and Digital Content, 23-25 Sept. 2016, Beijing, China.

2. http://www.rysavy.com, "LTE to 5G: Cellular and Broadband Innovation", Mobile Broadband Transformation, Rysavy Research/5G Americas, August 2017.

3. Mohammad Meraj ud in Mir, Sumit Kumar, "Evolution of Mobile Wireless Technology from 0G to 5G", International Journal of Computer Science and Information Technologies, Vol. 6 (3), 2015, pp.2545-2551.

4. Paschal A. Ochang, Philip J. Irving, "Evolutionary Analysis of GSM, UMTS and LTE Mobile Network Architectures", World Scientific News 54 (2016), pp.27-39.

5. Muhsin, Rina Pudji Astuti, "Dual-Cross-Polarized Antenna Decoupling for $43 \mathrm{GHz}$ Planar Massive MIMO in Full Duplex Single Channel Communications", International Journal of Advanced Computer Science and Applications, Vol. 10, No. 4, pp. 364-370, April 2019.

6. Hongtao Lu, Shihai Shao, Youxi Tang, "Self-mixed self-interference analog cancellation in full-duplex communications", Information Sciences (China) 59 (4), pp. 3737-3741, February 2015.

7. Adam Narbudowicz, Giuseppe Ruvio, and Max J. Ammann, "Passive Self-Interference Suppression for Single Channel Full-Duplex Operation", Accepted for publication in IEEE Wireless Communications Magazine .

8. Marta Gatnau Sarret, Gilberto Berardinelli, Nurul H. Mahmood, Marko Fleischer, Preben Mogensen and Helmut Heinz, "Analyzing the potential of full duplex in 5G ultra-dense small cell networks", EURASIP Journal on Wireless Communications and Networking (2016) 2016:284

9. A. Le, L. Tran, X. Huang \& Y. Guo, "Analog Least Mean Square Loop for Self-Interference Cancellation: Implementation and Measurements," in 29th IEEE International Telecommunication Networks and Applications Conference (ITNAC), 2019, pp. 1-6.

10. Jianshu Zhang, Omid Taghizadeh Motlagh, Jian Luo, and Martin Haard, "Full Duplex Wireless Communications with Partial Interference Cancellation", IEEE Asilomar 2012, pp. 1295-1299.

11. Tingjun Chen, Mahmood Baraani Dastjerdi, Jin Zhou, Harish Krishnaswamy, Gil Zussman, "Wideband Full-Duplex Wireless via Frequency Domain Equalization: Design and Experimentation", MobiCom '19, October 21-25, 2019, Los Cabos, Mexico.

12. Linyan Guo, Ming Deng, Qisheng Zhang, Xinyue Zhang, and Zhenzhong Yuan, "Dual-Polarized On-Chip Antenna for $300 \mathrm{GHz}$ Full-Duplex Communication System", Hindawi, International Journal of Antennas and Propagation Volume 2017.

13. R. Thandaiah Prabu and V. Thulasi Bai, "Design of Eight Element

Published By:

Blue Eyes Intelligence Engineering and Sciences Publication Vol. 8, Issue 1, pp. 936-941, May 2019. 2014. Magazine, Vol. 53, No. 9, 56-63, 2015. 2018.
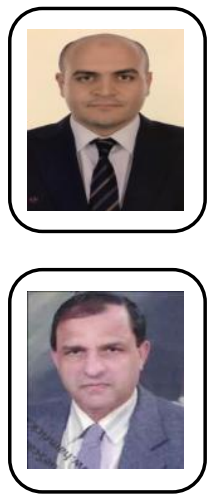
world-wide!" International Journal of Recent Technology and Engineering (IJRTE),

14. M. Duarte, A. Sabharwal, V. Aggarwal, R. Jana, K. K. Ramakrishnan, C. W. Rice, and N. K. Shankaranarayanan, "Design and characterization of a full-duplex multiantenna system for wifi networks," IEEE Trans. Veh. Technol., Vol. 63, No. 3, pp.1160-1177,

15. Areeba Ayesha, Shabbir Majeed Chaudhry, "Self-Interference Cancellation for Full-Duplex Radio Transceivers Using Extended Kalman Filter", National Academy Science Letters (2020).

16. Chung, M., M. S. Sim, J. Kim, D. K. Kim, and C.-B. Chae, "Prototyping real-time full duplex radios," IEEE Communications

17. Deng, Y., K. J. Kim, T. Q. Duong, M. Elkashlan, G. K. Karagiannidis, and A. Nallanathan, "Full-duplex spectrum sharing in cooperative single carrier systems," IEEE Transactions on Cognitive Communications and Networking, Vol. 2, No. 1, 68-82, 2016.

18. Xia, X., K. Xu, Y. Wang, and Y. Xu, "A 5G-enabling technology: Benefits, feasibility, and limitations of in-band full-duplex MIMO", IEEE Vehicular Technology Magazine, Vol. 13, No. 3, 81-90,

\section{AUTHORS PROFILE}

Ehab A. Hegazy, received B.Sc in Electrical \& computer engineering from Higher Technological institute, $10^{\text {th }}$ of Ramadan City, ,Egypt in 2004. He is currently working towards M.Sc. degree in Electrical Engineering from Al_Azhar University. His research interest includes mobile communication, microwave engineering planning, and antennas.

Mohamed Bakry EL_MASHADE received the B.Sc degree in electrical engineering from Al_Azhar University, Cairo, in 1978, the M.Sc. degree in the theory of communications from Cairo University, in 1982, Le D.E.A. d'Electronique (Spécialité: Traitment du Signal), and Le Diplôme de Doctorat (Spécialité: Composants, Signaux et Systems) in optical communications, from USTL, L'Academie de Montpellier, Montpellier, France, in 1985 and 1987, respectively. He serves on the Editorial Board of several International Journals. He has also served as a reviewer for many international journals. He was the author of more than 60 peer-reviewed journal articles and the coauthor of more than 60 journal technical papers as well as three international book chapters. He won the Egyptian Encouraging Award, in Engineering Science, two times (1998 \& 2004). He was included in the American Society 'Marquis Who's Who' as a 'Distinguishable Scientist' in 2004, and in the International Biographical Centre of Cambridge (England) as an 'Outstanding Scientist' in 2005. He has received the following message from "Who's Who in the World", "We are pleased to inform you that you have been named an official listee in the 2020 edition of Marquis Who's Who in the World ${ }^{\circledR}$. Congratulations on receiving this impressive distinction, reserved for less than $3 \%$ of professionals 